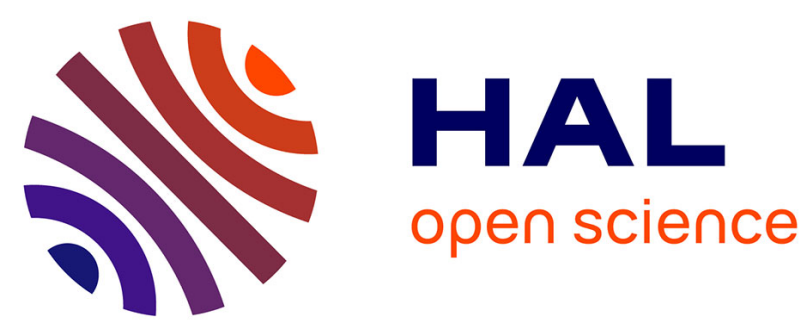

\title{
A strong inhibitor of gene expression in the 5', untranslated region of the pollen-specific LAT59 gene to tomato.
}

Catherine Curie, Sheila Mccormick

\section{- To cite this version:}

Catherine Curie, Sheila Mccormick. A strong inhibitor of gene expression in the 5' untranslated region of the pollen-specific LAT59 gene to tomato.. The Plant cell, 1997, 9 (11), 10.1105/tpc.9.11.2025 . hal-03084145

\section{HAL Id: hal-03084145 \\ https://hal.science/hal-03084145}

Submitted on 20 Dec 2020

HAL is a multi-disciplinary open access archive for the deposit and dissemination of scientific research documents, whether they are published or not. The documents may come from teaching and research institutions in France or abroad, or from public or private research centers.
L'archive ouverte pluridisciplinaire HAL, est destinée au dépôt et à la diffusion de documents scientifiques de niveau recherche, publiés ou non, émanant des établissements d'enseignement et de recherche français ou étrangers, des laboratoires publics ou privés.

\section{(ㅇ)(1) $\$$}

Distributed under a Creative Commons Attribution - NonCommercial - NoDerivatives 44.0 


\title{
A Strong Inhibitor of Gene Expression in the 5' Untranslated Region of the Pollen-Specific LAT59 Gene of Tomato
}

\author{
Catherine Curie ${ }^{1}$ and Sheila McCormick ${ }^{2}$ \\ Plant Gene Expression Center, United States Department of Agriculture-Agricultural Research Service and University of \\ California at Berkeley, 800 Buchanan Street, Albany, California 94710
}

\begin{abstract}
Promoter sequences that direct pollen-specific expression have been previously identified in the LAT59 (for late anther tomato) gene. Here, we show that the LAT59 sequences encoding the $5^{\prime}$ untranslated region inhibit expression of reporter genes by $>\mathbf{2 0}$-fold in transient expression experiments and up to $\mathbf{3 0 0}$-fold after stable transformation. Inhibition occurred in somatic cells as well as in pollen. Our results indicate that the inhibitor still functions after pollen germination and therefore does not modulate the level of the LAT59 protein during pollen development. The presence of the leader sequence dramatically decreased mRNA accumulation but without affecting translation rate and mRNA stability. We believe that the leader inhibits transcription. We mapped the inhibitor to a region in the leader that coincides with a putative stem-loop and present evidence that this stem-loop participates in inhibition.
\end{abstract}

\section{INTRODUCTION}

The $5^{\prime}$ untranslated region (5' UTR) of a gene often can affect gene expression and frequently does so via translational control (Geballe et al., 1986; Kaspar et al., 1992; Kempe et al., 1993; Stripecke et al., 1994). In many viral and eukaryotic genes, the mechanisms underlying this process have been well documented and involve the presence of either secondary structures or upstream open reading frames (reviewed in Kozak, 1991). However, in a few cases, leader regions have been shown to act transcriptionally; examples include the Drosophila hsp22 heat shock gene, in which the first 20 nucleotides of the transcribed region contain overlapping transcriptional and translational control elements (Hultmark et al., 1986), and the human gastrin (Theill et al., 1987) and $\gamma$-globin (Amrolia et al., 1995) genes. In the last decade, transcriptional regulation by inhibiting elongation (often called attenuation) rather than initiation has also been documented in eukaryotes (reviewed in Wright, 1993). During attenuation, the RNA polymerase II complex pauses, usually early in the transcription process, in response to cellular or environmental conditions. Among the best characterized cases of transcriptional attenuation are the human c-myc gene, whose elongation is blocked upon cell differentiation (Bentley and Groudine, 1986), the murine adenosine deaminase gene that is regulated by transcription elongation in a tissue-dependent manner (Chinsky et al., 1989), and the

\footnotetext{
${ }^{1}$ Current address: Laboratoire de Biochimie et Physiologie Moléculaire des Plantes, ENSAM/CNRS/INRA, Place Viala, 34060 Montpellie Cedex 1, France.

2To whom correspondence should be addressed. E-mail sheilamc@ nature.berkeley.edu; fax 510-559-5678.
}

human immunodeficiency virus HIV-1 gene in which premature termination of transcription is relieved by the tat gene product (Kao et al., 1987).

Little is known about regulation by sequences located in the transcribed region of plant genes. To date, the clearest evidence for the presence of transcriptional cis-acting elements in the transcribed region comes from analysis of genes that encode thylakoid proteins. Bolle et al. (1994) used run-on transcription assays to show that the leader sequences of the PetE, PetH, and PsaF genes quantitatively influence expression and that, at least in the PsaF gene, the leader contains cis elements that can interact with nuclear factors. Both the pea and Arabidopsis genes encoding ferredoxin contain light-regulatory elements in their transcribed region (Dickey et al., 1992, 1994; Caspar and Quail, 1993; Bovy et al., 1995); however, it is not yet clear which of the transcriptional or post-transcriptional events is affected. Recently, a translational enhancer was identified in the 5' UTR of the maize alcohol dehydrogenase Adh1 gene that can confer higher expression under low-oxygen conditions (Fennoy and Bailey-Serres, 1995; Bailey-Serres and Dawe, 1996).

The LAT59 (for late anther tomato) gene is a member of the "late" genes (Mascarenhas, 1990) that are coordinately activated during the late phase of microsporogenesis, that is, after the first microspore mitosis (McCormick, 1991a). Studies to determine the mechanisms of pollen-specific gene expression have focused on promoter sequences. In all species in which regulation of late gene expression has been studied, pollen specificity is transcriptionally controlled by the proximal promoter region (Guerrero et al., 1990; Twell et al., 1991; Albani et al., 1992; Eyal et al., 1995; Weterings 
et al., 1995). However, there is also evidence that expression of late genes can be post-transcriptionally regulated. First, although the late genes are transcribed as early as microspore mitosis, the proteins they encode are thought to play their role only during pollen maturation and/or germination (Mascarenhas, 1990). Second, in several species, the transcriptional inhibitor actinomycin $D$ does not affect early pollen tube growth in vitro, whereas the translational inhibitor cycloheximide does, indicating that initial pollen tube growth mainly relies on preexisting mRNAs in these species (reviewed in Mascarenhas, 1993). There is evidence of posttranscriptional regulation for the maize $Z m 13$ gene, whose mRNA is only translated at anthesis, 10 days after it first appears (Mascarenhas, 1993), and a tobacco mRNA encoding a $69-\mathrm{kD}$ protein that is abundant in pollen tubes but whose translation is inhibited in mature pollen (Storchova et al., 1994).

These findings prompted interest in determining the mechanisms of post-transcriptional regulation of late genes. For example, Bate et al. (1996) recently showed that the LAT52 gene contains a translational enhancer in its $5^{\prime}$ UTR that upregulates expression specifically in the late stages of pollen maturation. In contrast, we observed that the sequence encoding the LAT59 $5^{\prime}$ UTR inhibits gene expression. In this study, we characterize the inhibitor activity of the LAT59 leader. We show that inhibition involves a putative stemloop structure but unexpectedly seems to be transcriptionally regulated. We use transient assays and stable transformation in somatic cells to show that LAT59 5' UTR inhibitor activity is not restricted to pollen. We show that $5^{\prime}$ UTR inhibitor activity is not modulated upon pollen germination.

\section{RESULTS}

\section{Characterization of an Inhibitor in the LAT59 and $\mathrm{Nt59}$ Leaders}

We previously characterized cis elements in the proximal promoter of the LAT59 gene that are necessary and sufficient to drive pollen-specific gene expression (Eyal et al., 1995). The constructs used for those experiments did not contain the sequence encoding the 5' UTR region of LAT59 because we had found that it negatively affected gene expression. To further characterize this region of the LAT59 gene, we created a translational fusion between the luciferase ( $L U C)$ open reading frame (OW et al., 1986) and LAT59 gene sequences by using the -115 minimal promoter (Eyal et al., 1995) and various portions of the sequence encoding the $5^{\prime}$ UTR (Figure 1): either the full-length 236-bp construct (59L), a 210-bp internal deletion (construct $59 \Delta 210$ ), or only the 10 most upstream base pairs (construct $59 \Delta \mathrm{L}$ ). We tested the activity of these constructs in transient expression assays by using particle bombardment of pollen, as previously described (Twell et al., 1989; Eyal et al., 1995).
In these experiments, the LUC plasmids were cobombarded with a $\beta$-glucuronidase (GUS) plasmid (see Methods) used as an internal control for the bombardment. The relative LUC activity obtained after transient expression in pollen is shown in Figure 1. Deletion of the majority of the leader region in both $59 \Delta 210$ and $59 \Delta \mathrm{L}$ resulted in a 20 -fold increase in LUC activity relative to the $59 \mathrm{~L}$ construct, demonstrating that the segment encoding the LAT59 5' UTR negatively controls gene expression.

We tested whether the inhibitor function of the LAT59 leader is conserved in Nt59, its tobacco homolog (Kulikauskas and McCormick, 1997). Nt59 shares $86 \%$ nucleotide identity with LAT59 in the coding region and $74 \%$ in the $5^{\prime}$ UTR sequence. The entire Nt59 $5^{\prime}$ UTR, starting at position +3 , was subcloned into $59 \Delta \mathrm{L}$ (construct $\mathrm{Nt59L}$ ) to produce a chimeric 5' UTR that retains the same context of transcription initiation as the LAT59 fusions (Figure 1). Nt59L inhibited expression 50 -fold relative to $59 \Delta \mathrm{L}$ in transient expression assays, demonstrating that the inhibitor function has been conserved between the two species.

\section{The LAT59 Inhibitor Is Active in Somatic Cells}

To determine whether inhibitor activity is pollen specific, we tested its activity in somatic cells. Because the LAT59 promoter is not active in somatic tissue, transcription of the LUC fusions was driven by the cauliflower mosaic virus (CaMV) $35 \mathrm{~S}$ promoter-enhancer. The two constructs, 35S/59L and $35 \mathrm{~S} / 59 \Delta \mathrm{L}$, shown in Figure 2, were designed so that the transcripts produced in somatic cells would be identical to the transcripts tested in pollen. The $35 \mathrm{~S} / 59 \mathrm{~L}$ and $35 \mathrm{~S} / 59 \Delta \mathrm{L}$ constructs were bombarded into tobacco BY-2 cells with a CaMV 355 promoter-GUS fusion as an internal control.

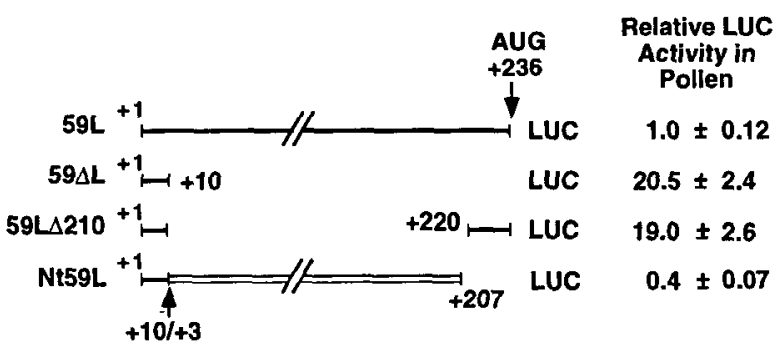

Figure 1. Identification of an Inhibitor in the LAT59 and Nt59 Leader Sequences.

Shown is a schematic representation of the MRNA transcripts produced under the control of the -115 LAT59 promoter (Eyal et al., 1995). Borders of the constructs and the translational fusion site with the LUC reporter gene are indicated relative to the transcription initiation site. Constructs were expressed by transient expression assay in tobacco pollen. Relative LUC activity represents the ratio between the test (LUC) and the reference (GUS) plasmids and is the mean of from at least six up to 21 independent experiments. 


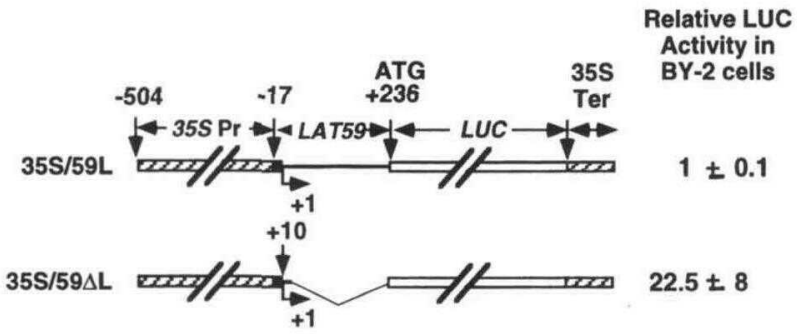

Figure 2. Activity of the Inhibitor in Transient Assays with Somatic Cells.

Shown are schematic representations of the $35 S$ promoter-LAT59 leader-LUC fusions containing either the LAT59 (positions -17 to +236 ) region (construct $35 \mathrm{~S} / 59 \mathrm{~L}$ ) or the LAT59 (positions -17 to +10 ) region (construct $35 \mathrm{~S} / 59 \Delta \mathrm{L}$ ). Constructs were transiently expressed in tobacco BY-2 cells. Relative LUC activity represents the ratio between the test (LUC) and the reference (GUS) plasmids and is the mean of nine independent experiments. $\mathrm{Pr}$, promoter; Ter, terminator.

Relative LUC activity is reported in Figure 2. Deletion of the leader sequence resulted in an increase in the level of expression similar to the one measured in transient expression in pollen. Therefore, we conclude that the inhibitor activity is not pollen specific.

\section{The LAT59 Inhibitor Is Active in Stable Transformants}

To confirm the presence of an inhibitor in the segment encoding the 5' UTR of the LAT59 gene, we examined the effect of its deletion on reporter gene expression in stably transformed tomato plants. For these experiments, we replaced the LUC gene with the Escherichia coli uidA gene encoding GUS to allow histochemical localization (Jefferson et al., 1987). Pollen harvested from the flowers of the primary transformants was assayed for GUS enzymatic activity, and the results are reported in Figure 3. We observed a ninefold increase in mean GUS activity upon deletion of the LAT59 leader, which is consistent with our transient expression results. However, there was a high variance, which is probably due to position effects and the relative weakness of the promoter (Eyal et al., 1995).

Because we had shown that the leader sequence could also inhibit expression in BY-2 cells, we investigated its effect on stable expression in transgenic BY-2 cell lines. Independent transformed $\mathrm{BY}-2$ cell lines were generated that express either the $35 \mathrm{~S} / 59 \mathrm{~L}$ or the $35 \mathrm{~S} / 59 \Delta \mathrm{L}$ fusion. An internal control (CaMV 35S-GUS fusion) on the same T-DNA was included to eliminate variability due to position effects and thus reduce the number of independent transformants required for the analysis. Transformed cell lines were assayed for LUC and GUS activity at the exponential phase (3 or 4 days). Figure 4 shows the results obtained from five and four independent transformants, respectively, for the $59 \mathrm{~L}$ and $59 \Delta \mathrm{L}$ constructs. Cell lines with a deleted leader $(35 \mathrm{~S} / 59 \Delta \mathrm{L})$ showed an average of 300 times higher relative LUC activity than those transformed with the full-length leader (35S/59L). This indicates that the region of the LAT59 gene encoding the 5' UTR strongly inhibits expression and confirms data obtained with the transient expression assay.

\section{Inhibitor Activity Is Not Alleviated during Pollen Germination}

The potential function of the LAT59 protein as a pectate lyase suggests that it may play an important role during pollen tube growth (Dircks et al., 1996). The LAT59 protein and its tobacco homolog, the Nt59 protein, show very high sequence homology ( $93.5 \%$ similarity at the amino acid level) (Kulikauskas and McCormick, 1997) as well as a similar pollen-specific pattern of expression; therefore, they are likely to play the same role in tomato and tobacco, respectively. In

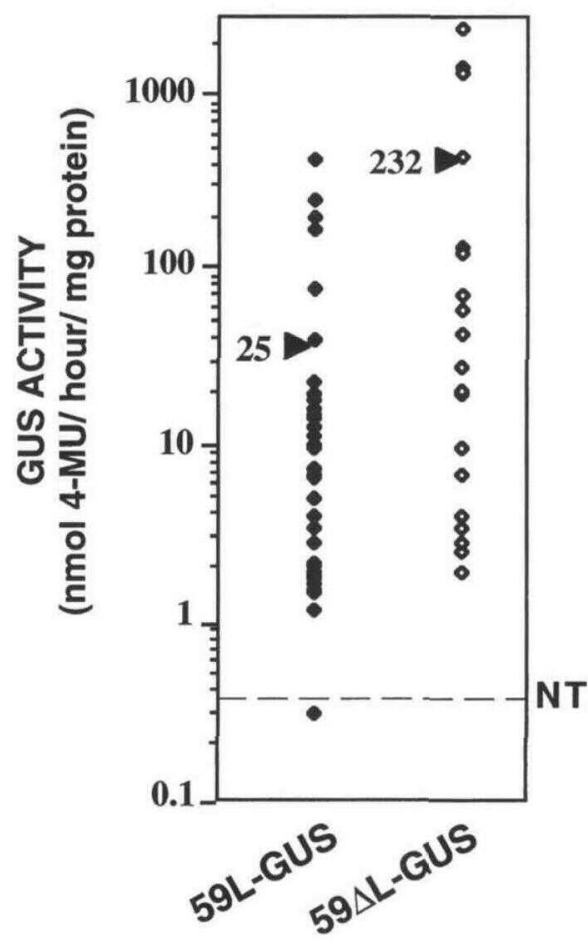

Figure 3. Effect of the LAT59 Leader on Reporter Gene Expression in Pollen of Stably Transformed Tomato Plants.

GUS expression levels were determined in transgenic tomato plants harboring LAT59 fused to the uidA reporter gene with (59L-GUS) or without (59AL-GUS) the LAT59 leader sequence. GUS levels in the pollen extract are represented in nanomoles of 4-methylumbelliferone (4-MU) generated per hour per milligram of protein. NT, untransformed control line. 

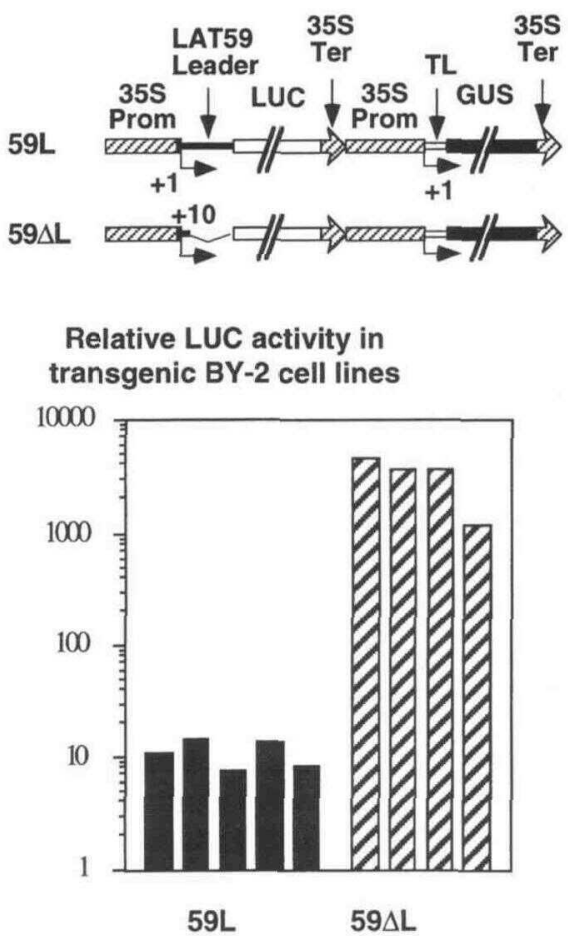

Figure 4. The LAT59 Leader Sequence Has a Strong Inhibitor Activity in Transgenic BY-2 Cells.

A schematic representation of the LUC (test) and GUS (reference) gene fusions present on the same T-DNA used to stably transform tobacco BY-2 cells is shown above. Relative LUC activity represents the ratio between LUC and GUS activities and is shown for independent transgenic cell lines below. Angled arrows indicate the transcription initiation sites. Prom, promoter; Ter, terminator; TL, tobacco mosaic virus leader sequence.

addition, we have shown that the inhibitor activity present in the LAT59 $5^{\prime}$ UTR is functionally replaced by the Nt59 5' UTR sequence. We wondered whether a change in inhibitor activity could control a differential expression between mature pollen and germinated pollen. First, we needed to establish the pattern of accumulation of LAT59 and of Nt59 in mature pollen and during germination. Protein extracts from mature and in vitro-germinated pollen were immunoblotted and probed with the anti-59 antibody. Figure $5 \mathrm{~A}$ shows that the antibody detected an $\sim 50-k D$ doublet in mature pollen extracts. After $15 \mathrm{hr}$ of pollen germination, the amount of the LAT59 protein increased, whereas the Nt59 protein level did not change.

To test for a regulatory role for the $5^{\prime}$ UTR, we measured the transcript level only in tobacco, because of the limited amount of germinated tomato pollen available. Tobacco total RNA from mature pollen and germinated pollen was probed with the Nt59 gene. Figure 5B shows an $\sim 2.5$-fold decrease in the steady state level of Nt59 mRNA upon ger- mination, after correction of the hybridization intensities with the loading control (ethidium bromide staining of rRNA). Extrapolation of this result to the LAT59 gene would indicate that the increase in LAT59 protein upon germination does not result from a decrease in the $5^{\prime}$ UTR inhibitor activity.

To verify the absence of a regulatory role for the LAT59 5' UTR inhibitor, we measured the effect of its deletion on transient gene expression in germinating pollen. Tobacco pollen was bombarded with either $59 \mathrm{~L}-\mathrm{LUC}$ or $59 \mathrm{\Delta L}$-LUC plasmids and then split into two batches. One batch was directly extracted, and the other batch was germinated overnight. Bombardment had no discernable effect on germination frequency. Relative LUC activity, obtained after correction for bombardment variations with the GUS internal control, was measured for the $59 \mathrm{~L}$ and $59 \Delta \mathrm{L}$ constructs in mature and germinated pollen. Results of this experiment are shown in Table 1. The role played by the leader in gene expression at each stage can be estimated by the ratio between the $59 \Delta \mathrm{L}$ and 59L LUC activities. For both mature and germinated pollen, the $59 \Delta \mathrm{L} / 59 \mathrm{~L}$ ratios were similar, although the LUC activity was higher in germinated pollen than in mature pollen. We also assayed pollen of three independent 59L-GUS transgenic tomato plants before and after in vitro germination. We found that the effect of the leader on GUS expression did not change after germination (data not shown). Because the leader inhibits reporter gene expression at a similar level in mature and germinated pollen, it is unlikely to be responsible for the increase in LAT59 protein levels after germination.

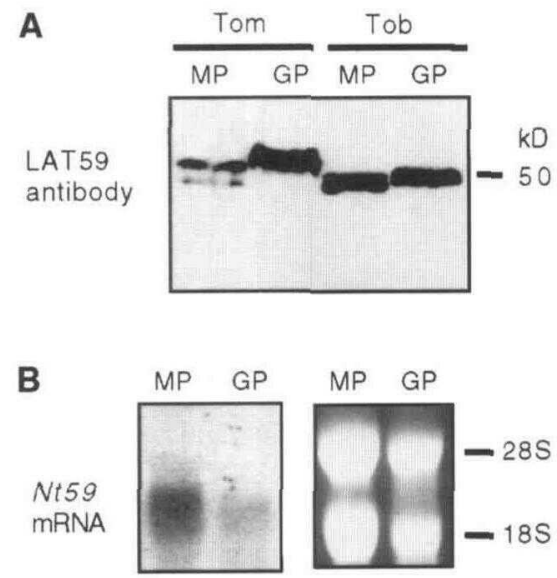

Figure 5. LAT59 and Nt59 Protein and Nt59 mRNA Steady State Levels during Pollen Development.

(A) Shown is an immunoblot of a gel containing $50 \mu \mathrm{g}$ of total protein from mature pollen (MP) and germinated pollen (GP) of tomato (Tom) and tobacco (Tob), probed with the LAT59 antiserum.

(B) Shown at right is ethidium bromide staining of a formaldehydeagarose gel containing $20 \mu \mathrm{g}$ of total RNA from mature pollen (MP) and germinated pollen (GP) of tobacco, showing $18 \mathrm{~S}$ and $28 \mathrm{~S}$ rRNAs. A blot of the same gel probed with the Nt59 cDNA is shown at left. 
Table 1. Comparison of Inhibitor Effect in Mature (MP) and Germinated Pollen (GP)

\begin{tabular}{|c|c|c|}
\hline \multirow[b]{2}{*}{ Construct } & \multicolumn{2}{|c|}{ LUC Activity (Light Units/ $\mu \mathrm{g}$ Protein) ${ }^{\mathrm{a}}$} \\
\hline & MP & GP \\
\hline $59 \mathrm{~L}$ & $280 \pm 90$ & $9,000 \pm 60$ \\
\hline $59 \Delta \mathrm{L}$ & $6,000 \pm 900$ & $120,000 \pm 4,000$ \\
\hline Ratio $\underline{59 \Delta \mathrm{L}}$ & 21 & 13 \\
\hline $59 \mathrm{~L}$ & & \\
\hline
\end{tabular}

${ }^{a}$ Results are from six independent bombardments.

\section{Sequences Encoding the LAT59 5' UTR Are Likely to Affect Transcription}

We initially tried to compare GUS mRNA and protein steady state levels in pollen of individual transgenic tomato plants expressing $59 \mathrm{~L}-\mathrm{GUS}$ or $59 \Delta \mathrm{L}-\mathrm{GUS}$. However, the high variability in the level of GUS mRNA did not correlate with the enzymatic activity measured, and we could not correct for this variability because the plants had not been transformed with an internal control. Because comparable levels of inhibition were obtained by transient assays in pollen and BY-2 cells, we opted to use BY-2 cells to study the mechanism of inhibition. Therefore, we measured the mRNA level and enzyme activity for the LUC and GUS genes in transgenic cell lines expressing $35 \mathrm{~S} / 59 \mathrm{~L}$ or $35 \mathrm{~S} / 59 \Delta \mathrm{L}$. We extracted mRNA from and conducted enzymatic assays with the same aliquot to avoid stage-dependent variation in expression. Figure 6 shows the results with a representative transformant of each fusion; similar results were obtained with four independent transformants. Figure 6A shows that the LUC activity is reduced in the presence of the leader, and Figure $6 \mathrm{~B}$ shows that there is less LUC mRNA when the leader is present. A comparison of the signals shows that $50 \mu \mathrm{g}$ of total RNA from the 59L transformant contains less LUC mRNA than 1 $\mu \mathrm{g}$ of total RNA from the $59 \Delta \mathrm{L}$ transformant. Therefore, we estimate that the difference in LUC mRNA between these two lines is $>50$. Calculations from the GUS enzymatic and mRNA levels indicate that the $59 \mathrm{~L}$ cell line has five times more expression than does the $59 \Delta \mathrm{L}$ cell line; thus, the steady state level of LUC mRNA is at least 250 times less when the sequence for the LAT59 $5^{\prime}$ UTR is present. We conclude that the LAT59 $5^{\prime}$ UTR inhibitor affects the cellular mRNA level by either decreasing transcription or increasing mRNA degradation.

The LAT59 and Nt59 $5^{\prime}$ UTRs contain predicted stemloop structures (PC Gene, RNA folding program). In LAT59, the stem-loop spans the region from +62 to +180 and has a calculated stability of $\Delta G=-47 \mathrm{kcal} \mathrm{mol}^{-1}$. Such stemloops in the $5^{\prime}$ transcribed region were found to inhibit translation initiation in several genes (Kozak, 1991). The predicted stem-loops in LAT59 and Nt59 prompted us to test whether the LAT59 5' UTR might affect translation as well as transcript accumulation.
Synthetic RNAs, with the LUC open reading frame fused either to the full-length LAT59 $5^{\prime}$ UTR or to its deleted $59 \Delta \mathrm{L}$ version, were produced and translated in a cell-free translation system. Figure 7 shows that both synthetic mRNAs are translated at a similar rate over $2 \mathrm{hr}$, reaching a plateau in $<1 \mathrm{hr}$. Results were similar whether the mRNAs were capped or uncapped and whether translation was performed in wheat germ extracts (Figure 7) or in rabbit reticulocyte lysates (data not shown).

We also examined the role of the LAT59 5' UTR on translation in protoplasts, because it was possible that the conditions of the in vitro assay did not allow the proper folding of the putative stem-loop. For these experiments, mRNA was introduced into protoplasts via electroporation (Callis et al., 1987; Gallie et al., 1989), and transient expression was monitored, allowing us to directly address post-transcriptional control mechanisms. The importance of a cap and a poly(A) tail for efficient translation in plant protoplasts has been demonstrated previously (Gallie, 1991). Capped and polyadenylated synthetic mRNAs were produced that contained a LUC fusion with LAT59 leader sequence, with or without the inhibitor element, using the vector PT7-LUC-A (Gallie $_{50}$ et al., 1991). Synthetic mRNAs were electroporated into BY-2 protoplasts, and LUC enzymatic activity was assayed after 4

A

\begin{tabular}{lrr}
\hline Cell line & $59 \mathrm{~L}$ & $59 \Delta \mathrm{L}$ \\
\hline $\begin{array}{l}\text { LUC Activity } \\
\text { (light Units/mg prot) }\end{array}$ & 1190 & 33360 \\
\hline $\begin{array}{l}\text { GUS Activity } \\
\text { (nM MU/min/mg prot) }\end{array}$ & 148 & 22 \\
\hline LUC/GUS & 8 & 1516 \\
\hline
\end{tabular}

B

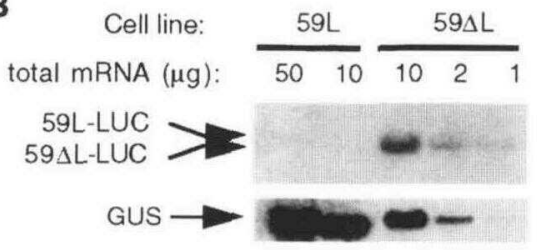

Figure 6. Effect of the LAT59 Leader Sequence on mRNA Level and GUS and LUC Activity in Transgenic BY-2 Cells.

mRNA and protein extracts were prepared from the same culture at exponential phase. Results from one transformant for each construct are shown.

(A) Enzymatic activities of 4-day-old BY-2 cell cultures expressing the 35S-GUS transgene and either 59L-LUC or 59AL-LUC. prot, protein; MU, 4-methylumbelliferone.

(B) RNA gel blot. The blot was first hybridized with LUC and then stripped before hybridization with GUS. The blot was exposed with a Phosphorlmager for $15 \mathrm{hr}$.

The smaller size of the $59 \Delta \mathrm{L} L U C$ mRNA is due to the deletion of $226 \mathrm{bp}$ of the sequence encoding the $5^{\prime}$ UTR. 


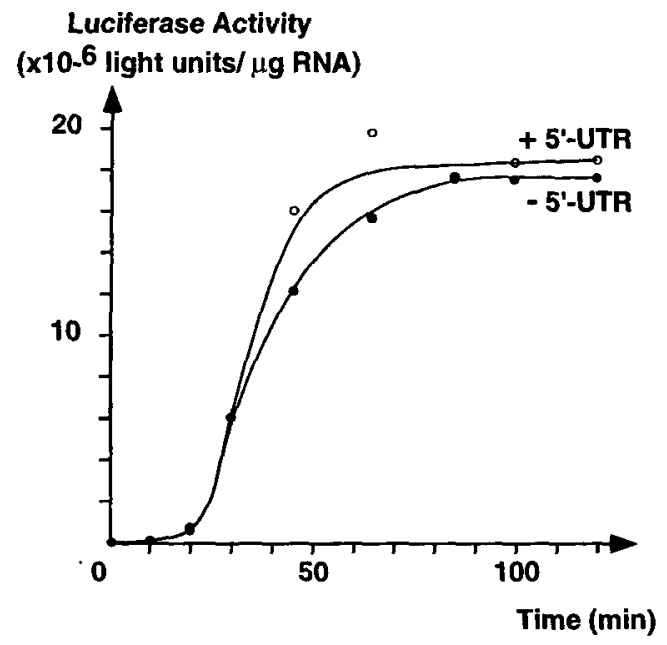

Figure 7. Effect of the $5^{\prime}$ UTR on the Rate of Translation in Vitro.

Capped synthetic LUC transcripts fused either to the full-length LAT59 5' UTR (+ 5'-UTR) or to $59 \Delta \mathrm{L}$ ( $\left(-5^{\prime}\right.$-UTR) were translated in a wheat germ extract. Aliquots of the reaction were taken at various time intervals and assayed for LUC activity.

$\mathrm{hr}$ of transient expression. Both mRNAs yielded the same amount of LUC activity ( $\sim 25$ light units $\mathrm{mg}$ of protein ${ }^{-1} \mathrm{hr}{ }^{-1}$ ). The LAT59 5' UTR clearly does not affect translation, because it had no effect on expression after in vitro translation or when introduced into protoplasts as MRNA, but it inhibited expression 20-fold when introduced as DNA.

We estimated the stability of the LUC transcript by determining the functional half-life in the presence or absence of the LAT59 5' UTR. The functional half-life of an mRNA is defined as the time required to reach $50 \%$ of the maximum LUC activity (Gallie, 1991). Synthetic mRNAs were electroporated into BY-2 protoplasts, and aliquots were harvested at various time intervals and assayed for LUC activity, as shown in Figure 8. LUC activity dropped after $7 \mathrm{hr}$, although the viability of the protoplasts remained constant over $24 \mathrm{hr}$ (Figure 8, open circles). If the leader decreases the stability of the mRNA, the accumulation of LUC should reach an earlier plateau when the 5' UTR is present on the message. Figure 8 shows that both transcripts led to approximately the same level of LUC activity and showed a similar functional half-life: $130 \mathrm{~min}$ in the presence of the $5^{\prime}$ UTR and $150 \mathrm{~min}$ in the absence of the $5^{\prime}$ UTR. Therefore, a difference in mRNA stability cannot explain the 20-fold difference in expression observed in transient assays with tobacco BY-2 protoplasts. We conclude that the LAT59 $5^{\prime}$ UTR inhibitor does not act via alteration of mRNA stability. Having demonstrated that neither the efficiency of translation nor the stability of the transcript is affected by the $5^{\prime}$ UTR, we indirectly show that inhibition occurs through a transcriptional mechanism.

\section{Mapping of the Inhibitor Element(s) - Implication of the Stem-Loop Structure}

To define sequences that are involved in the inhibition, we derived a series of $3^{\prime}$ to $5^{\prime}$ and internal deletions in the leader region of the $59 \mathrm{~L}$ construct. The most informative of these constructs and their effect on LUC expression in pollen are shown in Figure 9. Removal of the sequence upstream of the secondary structure from positions +10 to +56 (construct 59L1) had no effect on LUC expression. On the contrary, deletion of the downstream region from +189 to the translational fusion site (construct 59L2) resulted in a threefold increase of LUC expression. We observed a similar derepression level with 59L3, whose translational context had been restored by addition of the original LAT59 sequence flanking the AUG. These results indicate that the $(+189$ to +220$)$ region participates in the inhibition. Deleting the internal region from +10 to +156 (construct $59 \mathrm{~L} 4$ ) entirely eliminates the inhibition. Thus, essential elements reside upstream of position +156 , and the downstream regulatory region alone $(+189$ to +220$)$ cannot inhibit expression. In turn, further $3^{\prime}$ to $5^{\prime}$ deletions up to positions +136 and +91 (constructs $59 L 5$ and 59L6) largely derepress expression.

We conclude from these experiments that the central region of the leader is essential for the inhibitor activity although not sufficient, because a small region located in the 3' part of the leader participates in achieving full-level inhibition. The fact that a large region of the leader is involved in the inhibitor activity and that this region contains a putative stem-loop (from positions +62 to +180 ) raised the possibility that this stem-loop mediates the inhibition.

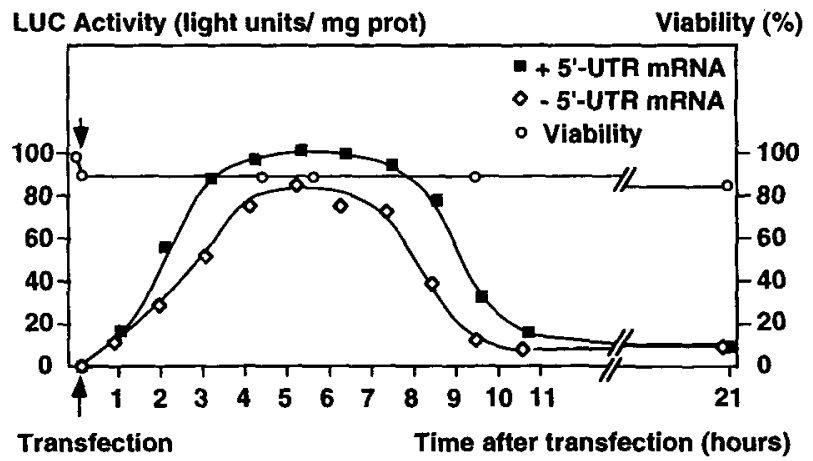

Figure 8. Effect of the $5^{\prime}$ UTR on the Stability of LUC mRNA in Electroporated BY-2 Protoplasts.

Capped and polyadenylated synthetic LUC transcripts, containing the full-length LAT59 $5^{\prime}$ UTR (+ 5'-UTR) or a deleted version retaining the last 50 nucleotides ( $-5^{\prime}-\mathrm{UTR}$ ), were electroporated into BY-2 protoplasts. The arrows indicate the time of electroporation. Aliquots were taken at various time intervals, and LUC activity was as sayed (left scale). The viability of the protoplasts was measured in the same aliquots (right scale). prot, protein. 


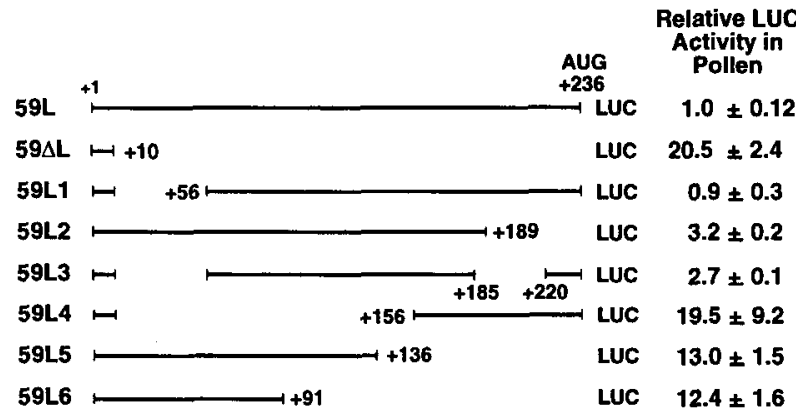

Figure 9. Deletion Analysis of the LAT59 Leader Region.

A schematic representation of the mRNA transcripts produced under the control of the -115 LAT59 promoter is shown. Borders of the constructs and the translational fusion site with the $L U C$ reporter gene are indicated relative to the transcription initiation site. Constructs were introduced into tobacco pollen via particle bombardment. Relative LUC activity represents the ratio between the test (LUC) and the reference (GUS) plasmids and is the mean of from at least six up to 21 independent experiments.

We used site-directed mutagenesis to test whether the putative stem-loop or the sequence itself is important for the inhibitor activity. Alteration of a secondary structure by point mutations can be reversed by a second mutation that is complementary to the first one, resulting in an identical structure with an altered sequence. In this way, the effect on expression of a secondary structure can be dissociated from the effect of the sequence that constitutes it. Mutations resulting in destabilization of the $L A T 59$ putative stem-loop were introduced, singly or in combination with a complementary mutation, and their effect on expression was tested in pollen by using transient expression assays. To simplify the analysis, the mutations were made in the context of the $59 \mathrm{~L} 3$ construct, which lacks the $5^{\prime}$ and $3^{\prime}$ dispensable parts of the leader but still shows considerable inhibition $(6.2$ times relative to $59 \Delta \mathrm{L}$ ). The calculated stability of the $59 \mathrm{~L} 3$ leader is $-49 \mathrm{kcal} \mathrm{mol}^{-1}$, and the stability of each mutated leader sequence is indicated in Table 2 . We could not identify pairs of mutations in which both members would significantly affect the calculated stability of the structure, probably because of the length of the stem-loop and its capacity to fold in alternative structures. Therefore, we tested three sets of mutations (M1 through M3, represented in Figure 10A) and were careful to keep the ratio between the AT and GC pairs constant between the wild-type and the double mutant sequences (see Methods).

The effects of the mutations on LUC activity are shown in Figure 10B. M1 and M1C mutations each derepressed expression more than twofold, whereas when both mutations were present, the inhibition level increased to four times higher than did the 59L3 sequence. This increase is consistent with the higher stability of the double mutant. Mutation
M2 derepressed expression more than did M2C, but the double mutant M2M2C partially restored the inhibition. Similarly, the double mutant M3M3C derepressed expression to a lesser extent than did $\mathrm{M} 3 \mathrm{C}$ alone. Therefore, in all three regions of the stem-loop, inhibitor activity of the double mutant is higher than one or both of the single mutations alone. This strongly supports the existence of a secondary structure in the leader and suggests that this structure mediates the inhibition. How the role of this stem-loop can be reconciled with a transcriptional control is discussed later in this article.

\section{DISCUSSION}

We identified an inhibitor element in the tomato LAT59 gene leader and showed that the inhibition is functionally conserved in the leader of its tobacco homolog Nt59. Using transient expression in pollen, we defined two functionally different domains in the leader that account for the inhibitor activity. One large domain, located in the center of the leader, mediates a greater than sixfold inhibition and is essential for the inhibitor function. This domain encompasses a putative stem-loop structure spanning sequences from positions +62 to +180 . That mutations affecting the sequence but conserving the secondary structure show inhibition strongly supports the formation of this stem-loop in vivo and suggests that it mediates the inhibition, as does the fact that a very similar stem-loop can be predicted in the leader of $N+59$.

However, in BY-2 cells, three lines of evidence demonstrate indirectly that the inhibitor exerts its control at the transcriptional level. (1) The steady state mRNA level is lowered by the LAT59 leader, as shown by RNA gel blot experiments with transgenic BY-2 cell lines, and thus parallels the decrease in gene expression caused by the leader sequence.

\begin{tabular}{lc}
\hline \multicolumn{2}{l}{ Table 2. Predicted Stability of Stem-Loop Mutants } \\
\hline Construct & $\Delta G\left(\mathrm{kcal}^{\mathrm{mol}}{ }^{-1}\right)^{\mathrm{a}}$ \\
\hline $59 L$ & -60.6 \\
$59 \Delta \mathrm{L}$ & $\sim 0$ \\
$59 L 3$ & -49.7 \\
- M1 & -46.6 \\
- M1C & -52.2 \\
- M1M1C & -62.1 \\
- M2 & -39.2 \\
- M2C & -39.3 \\
- M2M2C & -48.9 \\
- M3 & -40.6 \\
- M3C & -37.7 \\
- M3M3C & -51.2 \\
\hline
\end{tabular}

a Predicted stability calculated using the PC Gene RNA folding program, according to the Zucker algorithm.

${ }^{\mathrm{b}}$ Dashes indicate that the mutations were introduced into $59 \mathrm{~L} 3$. 
A

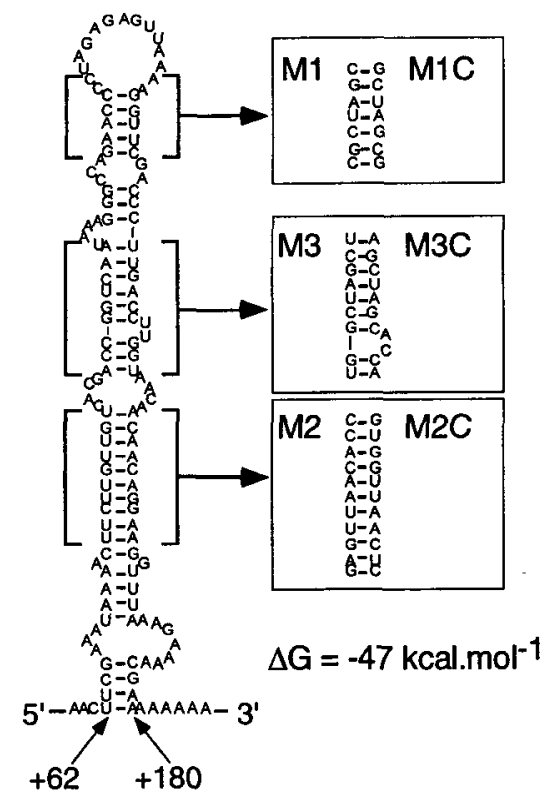

B

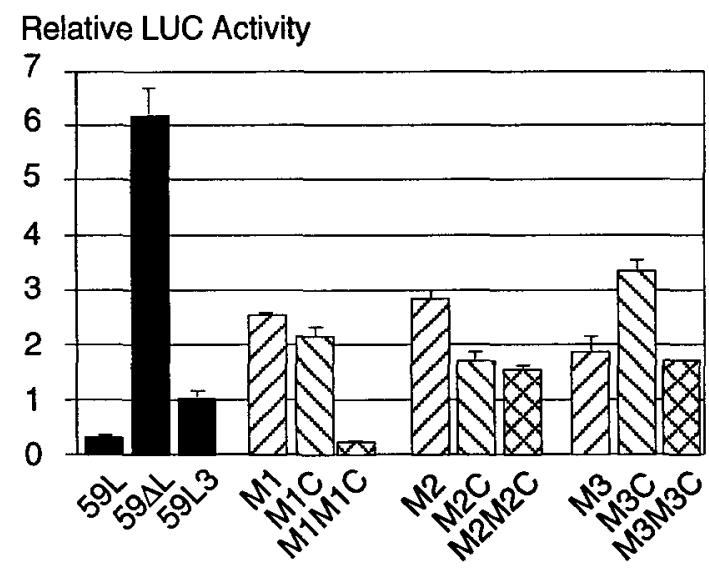

Figure 10. Site-Directed Mutagenesis of the LAT59 Putative StemLoop Structure.

(A) The putative stem-loop structure of the LAT59 leader. Mutations $M 1, M 2$, and $M 3$, and $M 1 C, M 2 C$, and $M 3 C$ (C for complementary mutation) were introduced in the context of the 59L3 construct, and their sequences are indicated to the right of the stem-loop structure. Numbers indicate the nucleotide position relative to the transcription start site.

(B) Relative LUC activity after transient expression in tobacco pollen. Results are the mean \pm SD of six independent experiments. Relative LUC activity obtained with the 59L3 construct was set to 1 . M1M1C, M2M2C, and M3M3C correspond to double mutants.

(2) Both in vitro and in vivo translation assays failed to show an effect of the 5' UTR on translation efficiency. Points (1) and (2) together clearly exclude an effect of the $5^{\prime}$ UTR on translation. (3) The LAT59 5' UTR does not significantly alter the mRNA functional half-life, as determined by time-course experiments in protoplasts electroporated with mRNA. Hence, mRNA instability cannot account for the inhibition. Future work will include run-on transcription assays to test directly for transcriptional control mediated by the leader sequence in these cells. But more importantly, we need to investigate whether the results obtained in BY-2 cells are relevant to pollen. Because the LAT59 gene is specifically expressed in pollen, it is conceivable that pollen factors might differentially control the inhibitor activity.

Secondary structures that are located in the $5^{\prime}$ region of mRNA have been shown to inhibit translation in eukaryotes (Kozak, 1991). However, it is most unusual that regions of dyad symmetry in the corresponding DNA would play a role in controlling gene expression. One plausible explanation for our results could be that the LAT59 leader affects transcription elongation rather than transcription initiation. It is then easy to imagine how such a secondary structure could be an obstacle for the RNA polymerase and prevent its progression. Regions of dyad symmetry have been shown to occur directly upstream of an RNA polymerase II pausing site in C-myc (Bentley and Groudine, 1988), although their role in the attenuation process has not been shown.

The c-myc attenuation site has been mapped to a T-rich sequence, as have other characterized attenuation sites. This is reminiscent of the bacterial rho-independent terminators that are composed of a stem-loop followed by a sequence rich in T residues (d'Aubenton Carafa et al., 1990). The second domain in the LAT59 leader that is involved in the inhibitor activity is located downstream of the stemloop, between positions $+\mathbf{1 8 5}$ and +220 . This domain is not able to inhibit expression on its own but is necessary to achieve full-level inhibition. Interestingly, these 35 bp are extremely AT rich in the LAT59 and Nt59 genes (94 and $91 \%$ $A T$, respectively). Whether the two defined domains in the LAT59 leader can act as a premature termination site for the RNA polymerase requires further investigation. Position dependence of the inhibitor element relative to the promoter will be tested, because it has been shown to affect the c-myc attenuator function in Xenopus oocytes (Roberts and Bentley, 1992). The fact that the inhibitor functions independently of the linked promoter (LAT59 or CaMV 35S) suggests that it does not interfere with elements of the basic transcriptional machinery but rather supports a role in controlling elongation.

Why does the LAT59 gene have this inhibitor? Inhibition is certainly not a general feature of the leaders of late pollenexpressed genes. We found at most a twofold level of inhibition when the leader region of the related LAT56 gene was tested in transient expression assays (data not shown). The presence of the LAT52 leader enhances expression (Bate et al., 1996).

Two hypotheses of regulation via the inhibitor element were considered. (1) Inhibition that occurs in mature pollen could be alleviated during germination to allow for the accumulation of the LAT59 protein. However, we found that the steady state mRNA level of the Nt59 gene, its tobacco ho- 
molog, decreases upon germination, indicating that there is not transcriptional upregulation of these genes during pollen germination and suggesting that the increase in LAT59 protein occurs via a post-transcriptional mechanism. Furthermore, we found no significant modulation of the activity of the $5^{\prime}$ UTR inhibitor upon germination in transient expression experiments. (2) Pectate lyases in pollen are thought to be involved in pollen tube growth either by destabilizing the pectic linkages to help construct the wall or by facilitating the penetration of the tube through the pectin-rich matrix of the style. Although there are many pectate lyase-like genes expressed in pollen (McCormick, 1991a; Dircks et al., 1996), it is not known whether there are differences in substrate specificity and whether the precise functions of the proteins differ. Perhaps the expression of some pectate lyase-like proteins must be tightly regulated in pollen. Similarly, if the product of LAT59 could compromise cell wall integrity, perhaps its expression must be prevented in somatic cells. Thus, inhibition by the leader might prevent expression in somatic tissues but allow expression in pollen. Consistent with this idea is the much more dramatic inhibition obtained in the transgenic BY-2 cells compared with transgenic tomato pollen.

An alternative interpretation is that the inhibitory sequence lacks a regulatory role and simply keeps LAT59 expression low at all times, while other mechanisms allow expression in pollen. Further study is needed to determine whether the inhibitor provides additional control over gene expression.

\section{METHODS}

\section{Plasmid Constructs}

The $59 \mathrm{~L}$ construct contains $115 \mathrm{bp}$ of the promoter and the entire 236-bp leader of the late anther tomato LAT59 gene and was created by translational fusion with the luciferase $(L U C)$ open reading frame (Ow et al., 1986) fused to the cauliflower mosaic virus (CaMV) 35S termination sequence. Construct $59 \Delta \mathrm{L}$ was described previously under the name p59 $\Delta$ ILUC (Eyal et al., 1995). The $59 \Delta$ L210 plasmid was obtained by cloning a double-stranded oligonucleotide corresponding to the LAT59 (positions +220 to +236 ) sequence into the $\mathrm{Ncol}$ site of $59 \Delta \mathrm{L}$. 59L2, 59L5, and 59L 6 are $3^{\prime}$ deletions generated after the introduction of an $\mathrm{Ncol}$ site by polymerase chain reaction (PCR) at positions $+189,+136$, and +91 , respectively, and subsequent deletion of the thus generated downstream Ncol fragment. To obtain the internal deletions 59L $1,59 \mathrm{~L} 3$, and 59L4, a Bcll restriction site was introduced at position +10 in 59L-LUC. The Bcll-Ncol fragment of the resulting plasmid was replaced by a PCR-made BcllNcol fragment corresponding to various lengths of the LAT59 $5^{\prime}$ untranslated region ( $5^{\prime}$ UTR). In the case of 59L3, the $3^{\prime}$ oligonucleotide used in the PCR reaction contained a 16-nucleotide tail sequence spanning a region (positions +220 to +236 ) of the $5^{\prime}$ UTR. $M 1$ to $M 3, M 1 C$ to $M 3 C$, and $M 1 M 1 C$ to $M 3 M 3 C$ mutations were created by site-directed mutagenesis (Kunkel et al., 1987) followed by replacing the wild-type $5^{\prime}$ UTR of $59 \mathrm{~L}$ by the mutated sequences. Nucleotide substitutions introduced are as follows (the dash corre- sponds to an unchanged nucleotide): $M 1,+109$ (CGCTAG) +114; M1C, +127 (GCTAGCG) + 133; M2, +75 (GAGT-AACACC) +85; M2C, +154 (GTGGTTAACTC) + 164; M3, +90 (TGGCTAGCT) +98; and $M 3 C,+139$ (AGCTAGCACCA) +149 .

The $(+3$ to +207$)$ fragment of the Nt59 gene encompassing most of the leader sequence was obtained by PCR, using genomic DNA as a template. The AfIIII-Ncol fragment was thus generated and then cloned into the $\mathrm{Ncol}$ site of $59 \Delta \mathrm{L}$.

The $35 \mathrm{~S} / 59 \mathrm{~L}$ and $35 \mathrm{~S} / 59 \Delta \mathrm{L}$ constructs, which were bombarded in tobacco BY-2 cells, contain the CaMV $35 \mathrm{~S}$ gene promoter-enhancer region $(-504$ to -19$)$ and include the TATA box, fused to either the $(-17$ to +236$) L$ region or the $(-17$ to +10$) \Delta L$ region of $L A T 59$ obtained by PCR

Plasmids used in the BY-2 protoplast transient experiments were generated from the pT7-LUC-A $A_{50}$ plasmid kindly provided by $D$. Gallie (University of California, Riverside; Gallie et al., 1991). Because the Dral site used for linearization before in vitro transcription is present twice in the LAT59 leader, the PT7-LUC-A $A_{50}$ plasmid was modified by the addition of a Bglll site between the Dral and EcoRI sites downstream of the $(A)_{50}$ sequence. The $(+21$ to +236$)$ and $(+185$ to +236$)$ LAT59 PCR fragments were inserted between the HindIII and Ncol sites of this modified pT7-LUC-A 50 .

$\beta$-Glucuronidase (GUS) fusions used in tomato (Lycopersicon esculentum cv VF36) stable transformation were as described previously (Eyal et al., 1995). $59 \mathrm{~L}$ and $59 \Delta \mathrm{L}$ constructs that were stably introduced into BY-2 cells were constructed in the pBin19 vector (Bevan, 1984). They contained a $L U C$ and a GUS reporter gene fusion in direct orientation in the T-DNA (Figure 4). The 35S-GUS fusion, used as internal control for the transformation experiment, corresponded to the excised Pstl fragment from the pRTL2-GUS vector (Carrington and Freed, 1990), whereas the 35S/59-LUC cassettes, containing either the $59 \mathrm{~L}$ or the $59 \Delta \mathrm{L}$ region, were identical to those used in transient expression assays in tobacco BY-2 cells.

\section{Transient Expression}

Particle bombardment experiments with tobacco pollen and tobacco BY-2 cell culture, as well as processing of the tissue for analysis of LUC and GUS activities, were as previously described (Twell et al., 1991) and later modified (Eyal et al., 1995). In each experiment, the test plasmid was cobombarded with a reference plasmid: $\mathrm{pBI} 223$ (Clontech, Palo Alto, CA) was used for assays with BY-2 cells, and pLAT56-12 (Twell et al., 1991) was used for assays of LAT59 constructs in pollen. Between six and 21 independent bombardments were performed with each construct.

Tobacco BY-2 cells (Nicotiana tabacum cv Bright Yellow 2) were maintained in culture, as described previously (An, 1985). Protoplasts were isolated essentially as described for the isolation of carrot protoplasts (Gallie et al., 1995), except that the isolation buffer contained 1\% cellulase Onozuka R10 (Yakult Honsha CD, Ltd., Tokyo, Japan) and $0.1 \%$ pectolyase Y23 (Seishin Pharmaceutical Co., Tokyo, Japan), and digestion was for $3 \mathrm{hr}$ at $28^{\circ} \mathrm{C}$ with $50 \mathrm{rpm}$ agitation. In vitro-synthesized $L U C$ mRNAs $(2 \mu \mathrm{g})$ were mixed with $10^{6}$ protoplasts (in $1 \mathrm{~mL}$ ) immediately before electroporation (pulse 5 msec at $150 \mathrm{~V}$, using a homemade unit of unknown capacitance). Electroporated protoplasts were then transferred to BY-2 medium (An, 1985) containing $200 \mathrm{mM}$ mannitol and assayed at the time intervals indicated. Processing of the protoplasts before the LUC assay was as described by Gallie et al. (1995). Protoplast viability was determined by staining with $1 \%$ fluorescein diacetate (Sigma). 


\section{In Vitro Pollen Germination}

Pollen from tomato or tobacco was added at a ratio of 1 to $2 \mathrm{mg} / \mathrm{mL}$ to germination medium described previously (Jahnen et al., 1989), except that $24 \%$ polyethylene glycol 3350 (Sigma) was used; it was swirled at $50 \mathrm{rpm}$ at $28^{\circ} \mathrm{C}$ for $15 \mathrm{hr}$. Germination was consistently near $100 \%$. Germinated pollen was collected on a nitrocellulose membrane by vacuum, washed several times with MSO medium (McCormick, 1991b), and processed for protein or RNA extraction, or for LUC and GUS enzymatic assays.

\section{Stable Transformation}

Constructs cloned into PBIN19 were introduced into tomato by using Agrobacterium tumefaciens LBA4404, as previously described (McCormick, 1991b). We generated 34 and 23 independent transformants, respectively, for the $59 \mathrm{~L}$ and $59 \Delta \mathrm{L}$ constructs. The pBin19 constructs were introduced into $\mathrm{BY}-2$ cells via Agrobacterium LBA4404, essentially as described by An (1985), except that $300 \mathrm{mg} / \mathrm{L}$ of carbenicillin and kanamycin were used. Four-day-old subcultures of BY-2 cells were cocultivated with a saturated culture of Agrobacterium for 3 days. After selection for 3 to 4 weeks, kanamycin-resistant calli were transferred to liquid medium and cultured at $28^{\circ} \mathrm{C}$. Aliquots of the cell cultures were sedimented at $700 \mathrm{~g}$ for $3 \mathrm{~min}$; the pellets were frozen in liquid nitrogen and lyophilyzed overnight. Cells were disrupted by vortexing in the presence of glass beads, as described previously (Van Hoof and Green, 1996), before analysis of LUC and GUS enzymatic activity or protein and RNA concentration.

\section{In Vitro Transcription/Translation}

mRNAs used in in vitro translation experiments and BY-2 protoplast transfections were synthesized in vitro by using the Ambion mMessage mMachine in vitro transcription kit (Ambion Inc., Austin, TX). RNA integrity was determined by agarose gel electrophoresis. In vitro translation reactions were performed with the Promega wheat germ extract, using optimum concentrations of $50 \mathrm{mM}$ potassium and 2 $\mathrm{mM}$ magnesium. Reactions were incubated at $25^{\circ} \mathrm{C}$. ${ }^{35} \mathrm{~S}$-methionine was incorporated in the translation products to allow their detection after separation by SDS-PAGE. The reaction $(1 \mu \mathrm{L})$ was assayed for LUC activity and protein concentration.

\section{Analysis of GUS and LUC Activities}

GUS enzymatic activity was assayed fluorometrically by using $2 \mathrm{mM}$ 4-methylumbelliferyl $\beta$-D-glucuronide as a substrate (Jefferson et al., 1987). GUS histochemical assays were performed with leaves, stems, roots, and flowers from the primary transformants of tomato, as previously described (Jefferson et al., 1987; Eyal et al., 1995). LUC activity was analyzed as previously described (Twell et al., 1991), except for the RNA electroporation into BY-2 protoplast experiments, when the more sensitive Promega luciferase assay system was used. Results are reported either as relative LUC activity, which represents the ratio between the test (LUC) and the reference (GUS) plasmids, or as LUC activity and GUS activity when corrected for variation in total protein content by using a bicinchoninic acid protein assay (Pierce, Rockford, IL).
Production of the LAT59 Peptide Fragment in Escherichia coli and Polyclonal Antibody Preparation

The LAT56 protein is $54 \%$ identical to the LAT59 protein, and the LAT56 antibody weakly cross-reacts with the LAT59 protein (Dircks et al., 1996). To generate an antibody that would specifically recognize LAT59, we used a short polypeptide from the LAT59 N-terminal extension that is not present in LAT56. The histidine-tagged LAT59 construct was generated in the pRSET vector (Invitrogen, San Diego, CA). The nucleotide sequence corresponding to amino acid positions 29 to 91 of LAT59 polypeptide was synthesized by PCR with a Nhel site at the $5^{\prime}$ end and with a TAG stop codon and a Hindlll site at the $3^{\prime}$ end. Because no overexpression of this 62-amino acid polypeptide could be obtained in $E$. coli, the so-called $E$. coli rare codons AGG and AGA (Chen and Inouye, 1994), encoding arginine and present at positions $8,9,10,56$, and 57 in the cloned sequence, were mutated by PCR to CGT and CGC, respectively, also encoding arginine.

The pRSET-derived construct was introduced into the $E$. coli BL21 (Novagen Inc., Madison, WI). Cells were induced with $0.3 \mathrm{mM}$ isopropyl $\beta$-D-thiogalactopyranoside for $2 \mathrm{hr}$ at $30^{\circ} \mathrm{C}$. The histidine-tagged LAT59 polypeptide was purified using the guanidine- $\mathrm{HCl}$-based protocol of the QIAexpress System (Qiagen Inc., Chatsworth, CA), followed by affinity chromatography on Ni-NTA resin (Qiagen). The protein sample in urea was desalted in PBS. Mice were injected with $80 \mu \mathrm{g}$ of protein in MPL plus TDM emulsion adjuvant (RIBI Immunochem Research, Hamilton, MT). Ascites fluids were induced by the sarcoma line T180 (ATCC accession number TIB 66) and directly used for immunodetection at a 1:5000 dilution. We verified that the anti-LAT59 antibody did not cross-react with the LAT56 protein in extracts prepared from insect cells infected with baculovirus expressing either the LAT56 or LAT59 cDNAs (Dircks et al., 1996; data not shown).

\section{Protein Extraction and Immunochemistry}

Mature pollen and in vitro-germinated polien from tomato were disrupted in a glass-glass homogenizer on ice using 3 volumes of protein extraction buffer (10 mM Tris, pH 7.4, 1 mM DTT, 1 mM EDTA, and $1 \mathrm{mM}$ Pefabloc [Boehringer Mannheim]). Cell debris was eliminated by centrifugation. Proteins were separated by SDS-PAGE and blotted to Hybond-ECL nitrocellulose membrane (Amersham) by electrotransfer. The membrane was blocked in TBS containing $2 \%$ glycine and 5\% milk, incubated with a 1:5000 dilution of LAT59 antibody, and detected using enhanced chemiluminescence developer following the manufacturer's instructions (Amersham).

\section{RNA Isolation and Hybridizations}

Isolation of total RNA from BY-2 cell lines was performed essentially as described by Newman et al. (1993). The lyophilyzed pellet was powdered by vortexing $1 \mathrm{~min}$ in the presence of 25 glass beads of 3 $\mathrm{mm}$ in diameter. After phenol extraction, RNA was precipitated with 0.2 volumes of $1 \mathrm{M}$ acetic acid and 0.7 volumes of ethanol. $\mathrm{LiCl}$ washes were replaced by $3 \mathrm{M}$ sodium acetate, $\mathrm{pH}$ 5.2. RNA was electrophoresed and blotted according to standard methods (Sambrook et al., 1989). Total RNA from mature and germinated pollen of tobacco was isolated using a $\mathrm{CsCl}$ method, according to Chirgwin et al. (1979). The entire open reading frames of the UidA, LUC, and Nt59 genes were labeled with phosphorus-32 by random priming (Feinberg 
and Vogelstein, 1984) and used as probes. Signals were detected using a Phosphorlmager (Molecular Dynamics, Sunnyvale, CA).

\section{ACKNOWLEDGMENTS}

We thank Daniel Gallie for providing advice and the pT7-LUC-A $A_{50}$ vector, Dinesh Kumar for the BY-2 cell culture and for helpful discussions, and Pamela Green for advice on RNA isolation from BY-2 cells. We thank Jorge Muschietti and Yoram Eyal for making available unpublished results and David Hantz for excellent greenhouse assistance. We thank Rima Kulikauskas for help with formatting the figures. We thank Paul Herzmark and all of the members of our laboratory for helpful comments on the manuscript. This work was supported by the United States Department of Agriculture-Current Research Information System Grant No. 5335-21000-008-00D. C.C. was partially supported by a Lavoisier Postdoctoral Fellowship sponsored by the French government.

Received April 7, 1997; accepted September 2, 1997.

\section{REFERENCES}

Albani, D., Sardana, R., Robert, L.S., Altosaar, I., Arnison, P.G., and Fabijanski, S.F. (1992). A Brassica napus gene family which shows sequence similarity to ascorbate oxidase is expressed in developing pollen. Molecular characterization and analysis of promoter activity in transgenic tobacco plants. Plant J. 2, 331-342.

Amrolia, P.J., Cunningham, J.M., Ney, P., Nienhuis, A.W., and Jane, S.M. (1995). Identification of two novel regulatory elements within the $5^{\prime}$-untranslated region of the human $\gamma$-globin gene. J. Biol. Chem. 270, 12892-12898.

An, G. (1985). High efficiency transformation of cultured tobacco cells. Plant Physiol. 79, 568-570.

Bailey-Serres, J., and Dawe, R.K. (1996). Both $5^{\prime}$ and $3^{\prime}$ sequences of maize Adh1 mRNA are required for enhanced translation under low-oxygen conditions. Plant Physiol. 112, 685-695.

Bate, N., Spurr, C., Foster, G.D., and Twell, D. (1996). Maturationspecific translational enhancement mediated by the $5^{\prime}$ UTR of a late pollen transcript. Plant J. 10,613-623.

Bentley, D.L., and Groudine, M. (1986). A block to elongation is largely responsible for decreased transcription of c-myc in differentiated HL60 cells. Nature 321, 702-706.

Bentley, D.L., and Groudine, M. (1988). Sequence requirements for premature termination of transcription in the human c-myc gene. Cell 53, 245-256.

Bevan, M. (1984). Binary Agrobacterium vectors for plant transformation. Nucleic Acids Res. 12, 8711-8721.

Bolle, C., Sopory, S., Lübberstedt, T., Herrmann, R.G., and Oelmüller, R. (1994). Segments encoding 5 '-untranslated leaders of genes for thylakoid proteins contain cis-elements for transcription. Plant J. 6, 513-523.

Bovy, N., Van Den Berg, C., De Vrieze, G., Thompson, W., Weisbeek, P., and Smeekens, S. (1995). Light-regulated expression of the Arabidopsis thaliana ferredoxin gene requires se- quences upstream and downstream of the transcription initiation site. Plant Mol. Biol. 27, 27-39.

Callis, J., Fromm, M., and Walbot, V. (1987). Expression of mRNA electroporated in plant and animal cells. Nucleic Acids Res. 15, 5823-5831.

Carrington, J.C., and Freed, D.D. (1990). Cap-independent enhancement of translation by a plant potyvirus 5 ' nontranslated region. J. Virol. 64, 1590-1597.

Caspar, T., and Quail, P.H. (1993). Promoter and leader regions involved in the expression of the Arabidopsis ferredoxin A gene. Plant J. 3, 161-174.

Chen, G., and Inouye, M. (1994). Role of the AGA/AGG codons, the rarest codons in global gene expression in Escherichia coli. Genes Dev. 8, 2641-2652.

Chinsky, J.M., Maa, M.C., Ramamurthy, V., and Kellems, R.E. (1989). Adenosine deaminase gene expression: Tissue-dependent regulation of transcriptional elongation. J. Biol. Chem. 264, 14561-14565.

Chirgwin, J.M., Przybyla, A.E., MacDonald, R.J., and Rutter, W.J. (1979). Isolation of biologically active ribonucleic acid from sources enriched in ribonuclease. Biochemistry 24, 5294-5299.

d'Aubenton Carafa, Y., Brody, E., and Thermes, C. (1990). Prediction of rho-independent Escherichia coli transcription terminators. A statistical analysis of their RNA stem-loop structures. J. Mol. Biol. 216, 835-858.

Dickey, L.F., Gallo-Meagher, M., and Thompson, W.F. (1992). Light regulatory sequences are located within the $5^{\prime}$ portion of the Fed-1 message sequence. EMBO J. 11, 2311-2317.

Dickey, L.F., Nguyen, T.-T., Allen, G.C., and Thompson, W.F. (1994). Light modulation of ferredoxin mRNA abundance requires an open reading frame. Plant Cell 6, 1171-1176.

Dircks, L.K., Vancanneyt, G., and McCormick, S. (1996). Biochemical characterization and baculovirus expression of the pectate lyase-like LAT56 and LAT59 pollen proteins of tomato. Plant Physiol. Biochem. 34, 509-520.

Eyal, Y., Curie, C., and McCormick, S. (1995). Pollen specificity elements reside in $30 \mathrm{bp}$ of the proximal promoters of two pollenexpressed genes. Plant Cell 7, 373-384.

Feinberg, A.P., and Vogelstein, B. (1984). A technique for radiolabeling DNA restriction endonuclease fragments to high specific activity. Addendum. Anal. Biochem. 137, 266-267.

Fennoy, S.L., and Bailey-Serres, J. (1995). Post-transcriptional regulation of gene expression in oxygen-deprived roots of maize. Plant J. 7, 287-295.

Gallie, D.R. (1991). The cap and poly(A) tail function synergistically to regulate mRNA translation efficiency. Genes Dev. 5, 2108-2116.

Gallie, D.R., Lucas, W.J., and Walbot, V. (1989). Visualizing mRNA expression in plant protoplasts: Factors influencing efficient mRNA uptake and translation. Plant Cell 1, 301-311.

Gallie, D.R., Feder, J., Schimke, R., and Walbot, V. (1991). Posttranscriptional regulation in higher eukaryotes: The role of the reporter gene in controlling expression. Mol. Gen. Genet. 228, 258-264.

Gallie, D.R., Caldwell, C., and Pitto, L. (1995). Heat shock disrupts cap and poly $(A)$ tail function during translation and increases mRNA stability of introduced reporter mRNA. Plant Physiol. 108, 1703-1713. 
Geballe, A.P., Spaete, R.R., and Mocarski, E.S. (1986). A cis-acting element within the $5^{\prime}$ leader of a cytomegalovirus $\beta$ transcript determines kinetic class. Cell 46, 865-872.

Guerrero, F.D., Crossland, L., Smutzer, G.S., Hamilton, D.A., and Mascarenhas, J.P. (1990). Promoter sequences from a maize pollen-specific gene direct tissue-specific transcription in tobacco. Mol. Gen. Genet. 224, 161-168.

Hultmark, D., Klemenz, R., and Gehring, W.J. (1986). Translational and transcriptional control elements in the untranslated leader of the heat-shock gene $h s p 22$. Cell 44, 429-438.

Jahnen, W., Lush, W.M., and Clarke, A.E. (1989). Inhibition of in vitro pollen tube growth by isolated S-glycoproteins of Nicotiana alata. Plant Cell 1, 501-510.

Jefferson, R.A., Kavanagh, T.A., and Bevan, M.W. (1987). $\beta$-Glucuronidase as a sensitive and versatile gene fusion marker in higher plants. EMBO J. 6, 3901-3907.

Kao, S., Calman, A.F., Luciw, P.A., and Peterlin, B.M. (1987). Antitermination of transcription within the long terminal repeat of HIV-1 by tat gene product. Nature 330, 489-493.

Kaspar, R.L., Kakegawa, T., Cranston, H., Morris, D.R., and White, M.W. (1992). A regulatory cis element and a specific binding factor involved in the mitogenic control of murine ribosomal protein L32 translation. J. Biol. Chem. 267, 508-514.

Kempe, E., Muhs, B., and Schäfer, M. (1993). Gene regulation in Drosophila spermatogenesis: Analysis of protein binding at the translational control element TCE. Dev. Genet. 14, 449-459.

Kozak, M. (1991). Structural features in eukaryotic mRNAs that modulate the initiation of translation. J. Biol. Chem. 266, 19867-19870.

Kulikauskas, R., and McCormick, S. (1997). Identification of the tobacco and Arabidopsis homologs of the pollen-expressed LAT59 gene of tomato. Plant Mol. Biol. 34, 809-814.

Kunkel, T.A., Roberts, J.D., and Zakour, R.A. (1987). Rapid and efficient site-specific mutagenesis without phenotypic selection. Methods Enzymol. 154, 367-382.

Mascarenhas, J.P. (1990). Gene activity during pollen development. Annu. Rev. Plant Physiol. Plant Mol. Biol. 41, 317-338.

Mascarenhas, J.P. (1993). Molecular mechanisms of pollen tube growth and differentiation. Plant Cell 5, 1303-1314.

McCormick, S. (1991a). Molecular analysis of male gametogenesis in plants. Trends Genet. 7, 298-303.

McCormick, S. (1991b). Transformation of tomato with Agrobacterium tumefaciens In Plant Tissue Culture Manual, K. Lindsey, ed
(Dordrecht, The Netherlands: Kluwer Academic Publishers), B6, pp. 1-9.

Newman, T.C., Ohme-Takagi, M., Taylor, C.B., and Green, P.J. (1993). DST sequences, highly conserved among plant SAUR genes, target reporter transcripts for rapid decay in tobacco. Plant Cell 5, 701-714.

Ow, D.W., Wood, K.V., Deluca, M., De Wet, J.R., and Helinsky, D.R. (1986). Transient and stable expression of the firefly luciferase gene in plant cells and transgenic plants. Science 234, 856-858.

Roberts, S., and Bentley, D.L. (1992). Distinct modes of transcription read through or terminate at the $\mathrm{c}-m y c$ attenuator. EMBO J. 11, 1085-1093.

Sambrook, J., Fritsch, E.F., and Maniatis, T. (1989). Molecular Cloning: A Laboratory Manual, 2nd ed. (Cold Spring Harbor, NY: Cold Spring Harbor Laboratory Press).

Storchova, H., Capkova, V., and Tupy, J. (1994). A Nicotiana tabacum mRNA encoding a 69-kDa glycoprotein occurring abundantly in pollen tubes is transcribed but not translated during pollen development in the anthers. Planta 192, 441-445.

Stripecke, R., Oliveira, C.C., McCarthy, J.E.G., and Hentze, M.W. (1994). Proteins binding to $5^{\prime}$ untranslated region sites: A general mechanism for translational regulation of mRNAs in human and yeast cells. Mol. Cell. Biol. 14, 5898-5909.

Theill, L.E., Wiborg, O., and Vuust, J. (1987). Cell-specific expression of the human gastrin gene: Evidence for a control element located downstream of the TATA box. Mol. Cell. Biol. 7, 4329-4336.

Twell, D., Klein, T.M., Fromm, M.E., and McCormick, S. (1989). Transient expression of chimeric genes delivered into pollen by microprojectile bombardment. Plant Physiol. 91, 1270-1274.

Twell, D., Yamaguchi, J., Wing, R.A., Ushiba, J., and McCormick, S. (1991). Promoter analysis of genes that are coordinately expressed during pollen development reveals pollen-specific enhancer sequences and shared regulatory elements. Genes Dev. 5 , 496-507.

Van Hoof, A., and Green, P.J. (1996). Premature nonsense codons decrease the stability of phytohemagglutinin mRNA in a positiondependent manner. Plant J. 10, 415-424.

Weterings, K., Schrauwen, J., Wullems, G., and Twell, D. (1995). Functional dissection of the promoter of the pollen-specific gene NTP303 reveals a novel pollen-specific and conserved cis-regulatory element. Plant J. 8, 55-63.

Wright, S. (1993). Regulation of eukaryotic gene expression by transcriptional attenuation. Mol. Biol. Cell 4, 661-668. 
A strong inhibitor of gene expression in the 5' untranslated region of the pollen-specific LAT59 gene to tomato.

C Curie and S McCormick

Plant Cell 1997;9;2025-2036

DOI 10.1105/tpc.9.11.2025

This information is current as of December 20, 2020

Permissions
eTOCs

CiteTrack Alerts

Subscription Information
https://www.copyright.com/ccc/openurl.do?sid=pd_hw1532298X\&issn=1532298X\&WT.mc_id=pd_hw1532 $298 X$

Sign up for eTOCs at:

http://www.plantcell.org/cgi/alerts/ctmain

Sign up for CiteTrack Alerts at:

http://www.plantcell.org/cgi/alerts/ctmain

Subscription Information for The Plant Cell and Plant Physiology is available at: http://www.aspb.org/publications/subscriptions.cfm 